\title{
Temas fundamentales de teología de la liberación*
}

\author{
Francisco de Aquino Júnior \\ Faculdade Católica de Fortaleza (FCF) y \\ Universidade Católica de Pernambuco (Unicap)
}

Las discusiones en torno a la teología de la liberación han aumentado en los últimos años. Tanto en lo que se refiere a su consistencia teórica como en lo que respecta a su densidad teológico-pastoral y a su relevancia histórico-social.

El debate sobre el método y sobre algunos temas epistemológicos, provocado por las críticas de Clodovis Boff, a pesar de su tono polémico, un tanto reduccionista y nominalista, explicitó un conflicto teórico silencioso entre los teólogos de la liberación. Ese conflicto atraviesa la historia de ese movimiento teológico, dio nueva visibilidad a la teología de la liberación, despertó un nuevo interés en ella y mostró la necesidad y la urgencia de retomarla y de reelaborar sus fundamentos teórico-teológicos ${ }^{1}$.

* Traducido del portugués por Aníbal Atalibal Lorca, S. J.

1. Cfr. C. Boff, "Teologia da Libertação e volta ao fundamento", REB 268 (2007), 1001-1022; L. C. Susin y E. Hammes, "A TdL e a questão dos seus fundamentos em debate com Clodovis Boff", REB 270 (2008), 277-299; L. Boff, "Pelos pobres e contra a estreiteza do método", $R E B \quad 271$ (2008), 701-710; F. Aquino Júnior, "Clodovis Boff e o método da TdL", REB 271 (2008), 597-613; C. Boff, "Volta ao fundamento: réplica", REB 272 (2008), 892-927; J. B. Libanio, "Excesso de zelo metodológico", REB 274 (2009), 472-482; F. Aquino Júnior, "A teologia como 'intellectus amoris'. A propósito da crítica de Clodovis Boff a Jon Sobrino", $R E B$ 274 (2009), 388-415; P. Wess, Deus, Cristo e os pobres. Libertação e salvação na fé à luz da Bíblia (São Bernardo do Campo: Nhanduti, 2011); F. Silvestrini Adão, "Nossa parte na herança: os frutos de um debate teológico no Brasil", REB 294 (2014), 264-299. 
La elección del nuevo obispo de Roma, el papa Francisco, y su proyecto de "una Iglesia pobre para los pobres", de alguna forma, retoman, reactualizan y proyectan sobre la Iglesia las intuiciones fundamentales, que están en la base del movimiento teológico-pastoral conocido como teología de la liberación ${ }^{2}$. Es oportuno destacar aquí la afirmación del actual prefecto de la Congregación para la doctrina de la fe, el cardenal Müller, en un libro escrito con Gustavo Gutiérrez y con un prefacio del papa Francisco: "La teología de la liberación no morirá mientras haya hombres que se dejen contagiar por la acción liberadora de Dios y que hagan de la solidaridad con los sufridores, cuya vida es oprimida, la medida de su fe y el impulso de su acción en la sociedad"3. En otro libro, escrito también con Gustavo Gutiérrez, Müller hace afirmaciones no menos incisivas y prospectivas sobre la teología de la liberación: "La teología de la liberación no es una sociología religiosamente guarnecida o un tipo de socioteología. Teología de la liberación es teología en sentido estricto"4; "a partir de las necesidades de la vida eclesial y a partir de la teología, debe decirse que la Iglesia, en el tercer mundo, pero también Iglesia como Iglesia universal, no puede renunciar a la continuación y al uso de la teología de la liberación"5.

Adicionalmente, la participación de cristianos y de creyentes de tradiciones y movimientos religiosos muy diversos en las múltiples luchas por la justicia del mundo torna siempre más actual, necesario y urgente el desarrollo de teologías de la liberación, con un horizonte cada vez más amplio - económico, social, político, cultural, genérico, sexual, étnico, ecológico, religioso e interreligioso, etc. Esto tanto desde el punto de vista de los creyentes que se incorporan a las luchas populares a partir de su fe -inteligencia y eficacia de la fe-como desde la perspectiva de las luchas y los movimientos populares por la justicia en el mundo -comprensión y prácticas de dignidad humana ${ }^{6}$.

2. Cfr. E. C. Bianchi, "Der Geist weht vom Süden her und drängt die Kirche hin zu den Armen", en M. Holztrattner, Innovation Armut, wohin führt Papst Franziskus die Kirche?, pp. 51-61 (Innsbrück: Tyrolia, 2013); J. C. Scannone, "Papa Francesco y la teologia del popolo", La Civiltá Cattolica 3930 (2014), 553-656; y F. Aquino Júnior, "Uma Igreja pobre para os pobres: Abordagem teológico-pastoral", Pistis \& Praxis 8/3 (2016), 631-657.

3. G. L. Müller, "A Teologia da libertação hoje", en G. L. Müller, Pobre para os pobres: A missão da Igreja, p. 34 (São Paulo: Paulinas, 2014).

4. G. L. Müller, "Experiência libertadora: estímulo para a teologia europeia", en G. L. Müller y G. Gutiérrez, Ao lado dos pobres: Teologia da libertação, p. 46 (São Paulo: Paulinas, 2014).

5. G. L. Müller, "A controvérsia em torno da Teologia da libertação", p. 109, en G. L. Müller y G. Gutiérrez, Ao lado dos pobres, o. c.

6. L. C. Susin (coord.), Terra prometida: Movimento social, engajamento cristão e teologia (Petrópolis: Vozes, 2001), y Teologia para outro mundo possível (São Paulo: 
Todo esto da una nueva actualidad a la teología de la liberación, que exige retomarla y reelaborar de manera crítica y creativa sus fundamentos teóricoteológicos. Por eso, en las siguientes páginas, nos proponemos tratar algunos temas fundamentales de la teología de la liberación. En particular, aquellos referidos a sus fundamentos epistemológicos: espiritualidad y eclesialidad, el interés y la orientación práctica, y el lugar social.

\section{Esclarecimientos previos}

\subsection{Aproximación epistemológica}

Conviene explicitar y determinar la clase de aproximación a la teología de la liberación que nos proponemos hacer. No vamos a tratar de su historia, de las elaboraciones de los diferentes temas teológico-sociales, de las controversias teológicas, eclesiales y sociales, de las diferentes corrientes y perspectivas de la teología de la liberación, de las tensiones y de los conflictos entre los teólogos de la liberación, de las diversas y hasta controvertidas concepciones y elaboraciones epistemológicas y metodológicas, etc. Sobre eso, hay una amplia bibliografía?

Nuestro interés es más modesto y más fundamental. Más modesto, porque se concentra en un aspecto de la discusión de la teología de la liberación. Más fundamental, porque trata de temas referidos a sus fundamentos epistemológicos.

La epistemología tiene que ver con el estudio del conocimiento. Puede ser definida como ciencia del conocimiento o filosofía de la ciencia, en el sentido amplio de la palabra. Más que de los pasos y los momentos o procedimientos del conocimiento de una determinada realidad, trata de problemas fundamentales

Paulinas, 2006); y B. de Sousa Santos, Se Deus fosse uma ativista dos Direitos Humanos (São Paulo: Cortez, 2014).

7. Cfr. L. Boff y C. Boff, Como fazer teologia da libertaçāo (Petrópolis: Vozes, 1998); J. B. Libanio, Teologia da libertação. Roteiro didático para um estudo (São Paulo: Loyola, 1987); J. J. Tamayo, "Teologias da libertação", en C. Floristán y J. J. AtayoAcosta, Dicionário de Conceitos Fundamentais do Cristianismo, pp. 820-827 (São Paulo: Paulus, 1999); L. Boff, J. Ramos Regidor y C. Boff, A teologia da Libertação: Balanço e perspectivas (São Paulo: Ática, 1996); E. Dussel, Teologia da libertação: Um panorama de seu desenvolvimento (Petrópolis: Vozes, 1999); L. C. Susin (coord.), O mar se abriu: Trinta anos de teologia na América Latina (São Paulo: Loyola, 2000); F. Aquino Júnior, A teologia como inteleç̧āo do reinado de Deus. O método da teologia da libertação segundo Ignacio Ellacuría (São Paulo: Loyola, 2010); J. O. Beozzo, "O êxito das teologias das libertaçōes e as teologias americanas contemporâneas", en A. Trevisiol (a cura di), In ascolto dell'America. Popoli, culture, religioni, strade per il futuro, pp. 327-380 (Roma: Urbanian University Press, 2014); cfr. "Teologia da libertação 40 anos: Balanço e perspectivas", Revista Horizonte 11 (2013), 32, disponible en http://periodicos.pucminas.br/index.php/ horizonte/issue/view/374. 
relativos al conocimiento: su naturaleza, su punto de partida, sus presupuestos, sus posibilidades, sus condicionamientos, su estructura, su diversidad, etc. Más que de un método concreto de conocimiento, trata de los presupuestos y de los principios teóricos fundamentales del conocimiento en general o de un conocimiento determinado. Aquí, hasta podríamos hablar de método. Pero, en ese caso, deberíamos distinguir entre un método concreto, que reflexiona y sistematiza el camino recorrido, en el conocimiento de una determinada realidad, y un método fundamental, que problematiza, explicita y justifica los presupuestos y los principios fundamentales del conocimiento.

En el caso específico de la teología, el método concreto trata de los momentos o procedimientos del proceso de elaboración de una teoría teológica: "auditus fidei - intellectus fidei - applicatio fidei"8; "mediación socio-analítica - mediación hermenéutica - mediación práctica", para citar los ejemplos más conocidos y consolidados entre nosotros. En cambio, el método fundamental primero trata del problema mismo del conocimiento que subyace, condiciona y determina, positiva o negativamente, el conocimiento desarrollado en ese o en otros métodos concretos. Las reflexiones siguientes se sitúan en ese ámbito de discusión fundamental.

\subsection{Complejidad}

Asimismo, conviene llamar la atención sobre la complejidad práctico-teórica de lo que se ha dado en llamar teología de la liberación. Esto es importante no solo porque, de hecho, hay una diversidad y pluralidad enorme de teologías de la liberación, que podría colocar en aprietos cualquier pretensión de hablar de una teología de la liberación. Sino también, y sobre todo, porque nos obliga a pensar sus fundamentos teórico-teológicos, de tal manera que esa complejidad y pluralidad que la caracteriza pueda ser abordada.

La expresión teología de la liberación es usada comúnmente para indicar tanto un movimiento eclesial, más o menos reflejo - un modo de ser Iglesia, un modo de vivir y celebrar la fe, un modo de actuar e intervenir en la sociedad, etc.-, como su momento más explícita y estrictamente reflexivo - una elaboración y formulación teórico-conceptual. Así, pues, sería una "praxis teologal" y una "teoría teológica", vividas y elaboradas a partir de los pobres y oprimidos, en el horizonte de su liberación. La formulación es ambigua, porque al final, la

8. Cfr. C. Boff, Teoria do método teológico, pp. 197-357 (Petrópolis: Vozes, 1998); J. Wicks, Introdução ao método teológico, pp. 35-38 (Sāo Paulo: Loyola, 1999); J. B. Libanio y A. Murad, Introdução à teologia: Perfil, enfoques, tarefas, pp. 93-97 (São Paulo: Loyola, 1996).

9. C. Boff, Teologia e prática. Teologia do político e suas mediações (Petrópolis: Vozes, 1993). 
teología es teoría y no práctica. La Iglesia de la liberación es mucho más amplia que la teología de la liberación. Esta es apenas un aspecto o momento de aquella. Pero la ambigüedad apunta al vínculo epistemológico constitutivo y esencial de la teología de la liberación (teoría) con la Iglesia de la liberación (praxis): la teología es un momento de la praxis eclesial y la praxis eclesial es determinante de la teología. En el fondo, son dos aspectos de un único movimiento, que se implican y se condicionan mutuamente, pero cuyo desarrollo puede darse a partir de un aspecto o de otro, y puede priorizar uno $u$ otro aspecto.

La "praxis teologal" remite a la vida humana, en todos sus aspectos y dimensiones, y a Dios, ya que es vivida en comunión con él. El énfasis puede recaer en un aspecto o en el otro. Así, se puede insistir más en el aspecto económico, social y político, en el cultural, en el de género, en el étnico-racial, en el ecológico, en el eclesial, en el ecuménico e interreligioso, etc. En buena medida, de aquí surgen las muchas teologías de la liberación: popular, feminista, negra, indígena, ecológica, interreligiosa, gay, etc. Asimismo, el contexto amplio donde se vive y se elabora la teología de la liberación - América Latina, África, Asia, Estados Unidos o Europa - introduce un aspecto o desafío regional preponderante, en el quehacer teológico - económico, político, cultural, religioso, etc. Eso sin mencionar el aspecto o desafío fundamental que, de alguna forma, pasa por todas las teologías de la liberación, relacionado con las condiciones materiales básicas de sobrevivencia. No sin razón, aunque sea discutible, muchas veces se toma la voz "pobre" como la expresión por antonomasia de todas las formas de injusticia y opresión.

La "teoría teológica" enfatiza la teorización de los procesos de liberación (praxis) o la liberación de las teorías y de los procesos de teorización (teoría). En este sentido, se puede hablar tanto de Teología de la liberación (Gustavo Gutiérrez) como de Liberación de la teología (Juan Luis Segundo), para citar dos obras clásicas de la teología de la liberación latinoamericana de la década de $1970^{10}$. Esas elaboraciones pueden darse en varios niveles. Es famosa la distinción y articulación de las tres "p" de la teología, de Clodovis Boff: teología popular, teología pastoral y teología profesional ${ }^{11}$. Más aún, el aspecto o la dimensión enfatizado por el quehacer teológico -económico, cultural, ambiental, genérico, religioso, etc. - acaba condicionando y determinando las mediaciones teóricas y prácticas asumidas y propuestas. Sin hablar de las opciones epistemológicas fundamentales, más presupuestas que elaboradas, referentes a la concepción del saber, los niveles del saber, el modo del saber, los intereses del saber, en fin, la relación del saber con la praxis, que condiciona el desarrollo de cualquier teoría

10. Cfr. G. Gutiérrez, Teologia da libertação: Prospectivas (São Paulo: Loyola, 2000); J. L. Segundo, Libertação da teologia (São Paulo: Loyola, 1978).

11. Cfr. C. Boff, Teoria do método teológico, o. c., pp. 597-609. 
teológica, tal como muestra el debate reciente sobre el método de la teología de la liberación.

Una vez aclaradas la complejidad de la teología de la liberación y el carácter epistemológico de nuestra aproximación, podemos ahora tratar los temas fundamentales de esa teología, antes indicados: su espiritualidad y eclesialidad, su orientación práctica y su lugar social.

\section{Espiritualidad y eclesialidad}

Comenzar por la espiritualidad y la eclesialidad de la teología de la liberación no es mera casualidad, ni una forma sutil de enfrentar o neutralizar las sospechas y críticas por no ser una teología espiritual y eclesial. O peor aún, por comprometer o negar la fe de la Iglesia. La razón es más fundamental. La teología de la liberación, como toda verdadera teología, nace, se desenvuelve y se mantiene, en última instancia, como inteligencia de una experiencia de Dios, dentro de una tradición eclesial concreta. Así lo afirma Libanio:

Toda escuela teológica se refiere a una espiritualidad. En el origen de toda teología, se percibe una experiencia espiritual de Dios. Las diferencias de las teologías se deben al carácter socio-histórico de esa experiencia fundante de Dios. Cuanto más profunda sea la experiencia y más corresponda a un determinado contexto, más oportunidad tiene la teología de imponerse eclesialmente. La teología de la liberación no es una excepción a esa regla ${ }^{12}$.

En efecto, nace de una profunda "experiencia de Dios en el pobre"13. En palabras de Leonardo Boff y Clodovis Boff: "Toda verdadera teología nace de una espiritualidad, vale decir, de un encuentro fuerte con Dios dentro de la historia. La teología de la liberación encuentra su nacimiento en la fe confrontada con la injusticia hecha a los pobres"14.

Más aún, según la formulación de Gustavo Gutiérrez:

En el punto de partida de toda teología se encuentra el acto de fe. No tanto como simple adhesión intelectual al mensaje, y sí como acogida vital del don de la Palabra escuchada en la comunidad eclesial, como encuentro con el Señor, como amor al hermano. Se trata de la existencia considerada en su totalidad. Acoger la Palabra, hacerla vida, gesto concreto, está en el inicio de cualquier comprensión de fe.

El camino para ser cristiano es el fundamento de la dirección que se toma para hacer teología. Por eso se puede decir que nuestra metodología es

12. J. B. Libanio, Teologia da libertação, o. c., p. 103.

13. Ibid., pp. 103-116.

14. L. Boff y C. Boff, Como fazer teologia da libertação, o. c., p. 15. 
nuestra espiritualidad (o sea, un modo de ser cristiano). La reflexión sobre el misterio de Dios sólo puede ser hecha siguiendo los pasos de Jesús ${ }^{15}$.

Lo propio de la teología de la liberación es lo que se convino en llamar "la experiencia de Dios en el pobre" o "la opción por los pobres", en el sentido amplio de la palabra - pobre, oprimido, marginado, excluido, etc. Eso, precisamente, constituye el núcleo de la experiencia judeo-cristiana de Dios, que, según la Escritura, aparece siempre como Dios de los pobres y los oprimidos. Esto es lo que hay de más religioso, sagrado, espiritual, trascendente, etc.

No es una eventualidad que Jesús resuma toda la ley en el amor a Dios y al prójimo (Mt 22,34-40) o, simplemente, en el amor al prójimo (Jn 15,12). Según la Escritura, ese es el criterio del amor a Dios (1 Jn 4,20), la condición y el criterio para heredar la vida eterna (Lc 10,25-37), o para participar en el banquete escatológico ( $c f r$. Mt 25,31-46). Por más que se quiera y se deba universalizar el amor cristiano, no se puede negar la centralidad y la prioridad que Jesús daba, en su praxis mesiánica, a los caídos a la orilla del camino, a los pobres, los enfermos, los pecadores públicos, los "posesos", los marginados - mujeres, niños, extranjeros, etc.

Con toda intención, el papa Francisco afirma, de modo claro, contundente y taxativo, que

No deben subsistir dudas ni explicaciones que debiliten este mensaje clarísimo. Hoy y siempre, "los pobres son los destinatarios privilegiados del Evangelio", y la evangelización dirigida gratuitamente a ellos es señal del Reino que Jesús vino a traer. Hay que afirmar sin rodeos que existe un vínculo indisoluble entre nuestra fe y los pobres ( $E G 48$ ).

No escuchar el clamor de los pobres, "nos coloca fuera del deseo del Padre y de su proyecto", y "la falta de solidaridad, en las necesidades, influye directamente sobre nuestra relación con Dios" ( $E G$ 187). La opción por los pobres pertenece, por tanto, al corazón del evangelio de Jesús y, en cuanto tal, es constitutiva - ino meramente consecutiva y opcional! - de la fe cristiana.

En esa tradición que viene de la experiencia que Israel tiene de Dios, que para los cristianos alcanza su plenitud en Cristo, y que, de modo más o menos intenso y fiel, se prolonga en la historia de la Iglesia, se sitúa la teología de la liberación. Dicho de manera clara y directa: la teología de la liberación se sitúa en la tradición de Jesús de Nazaret, una tradición suscitada, animada, sustentada y conducida por el Espíritu Santo - el Espíritu de Jesús de Nazaret. Esa tradición, no siempre conservada fielmente por el conjunto de la Iglesia, en particular por sus líderes, extrapola los límites inmediatos y visibles de la comunidad eclesial, y muchas veces entra en conflicto, más o menos directo e intenso, con las comuni-

15. G. Gutiérrez, A verdade vos libertará: Confrontos, p. 20 (São Paulo: Loyola, 2000). 
dades eclesiales de base y, sobre todo, con algunos ministros ordenados. A pesar de ello, esa tradición nunca se perdió del todo, en el conjunto de la Iglesia ${ }^{16}$.

Aquí se encuentra el carácter y la fuerza espiritual-eclesial de la teología de la liberación. Es teología cristiana en el sentido más auténtico y profundo de la palabra, porque se hace en el seguimiento y en la tradición de Jesús, porque es buena noticia del reinado de Dios y porque es teología de la Iglesia de Jesús. Las limitaciones y la necesidad de una mejor elaboración y desarrollo, en nada comprometen su espiritualidad y su eclesialidad fundamentales.

De todas maneras, puede objetarse desde el magisterio de la Iglesia, en concreto, desde las críticas de la Iglesia de Roma. A esa objeción se puede responder que la teología de la liberación, como cualquier teología, no es perfecta, ni absoluta, ni está pronta. Puede y debe ser mejorada, profundizada y reelaborada, y acoger y enfrentar, teórica y teológicamente, las críticas que se le han hecho. Pero como bien afirma el cardenal Müller, sus "grandes intuiciones" no son cuestionables ${ }^{17}$. En segundo lugar, la teología de la liberación está ampliamente respaldada por el magisterio de la Iglesia, a pesar de las reservas, las críticas y las advertencias de algunos obispos sobre determinadas afirmaciones de ciertos teólogos. Además del compromiso de muchos obispos con ese movimiento teológico-pastoral, de su sintonía con las conferencias de Medellín y Puebla y de los documentos de varias conferencias episcopales, la teología de la liberación nunca fue taxativamente condenada, ni siquiera en los momentos más críticos del conflicto con Roma ${ }^{18}$. En tercer lugar, conviene recordar que los últimos papas, incluido Benedicto XVI, han afirmado claramente la centralidad de la opción por los pobres en la revelación de la fe cristiana. Finalmente, no

16. Cfr. J. Comblin, A profecia na Igreja (São Paulo: Paulus, 2008), y O Espírito Santo e a Tradição de Jesus. Obra Póstuma (São Bernardo do Campo: Nhanduti, 2012).

17. Cfr. G. L. Müller, "A controvérsia em torno da teologia da libertação", en G. L. Müller y G. Gutiérrez, Ao lado dos pobres, o. c., p. 109.

18. Vale recordar aquí la afirmación del papa Juan Pablo II, en una carta a la conferencia episcopal de Brasil sobre los conflictos (CNBB 09/04/1986): "Na medida em que se empenha por encontrar aquelas respostas justas - penetradas de compreensāo para com a rica da Igreja neste País, tão eficazes e construtivas quanto possível e aos mesmo tempo consoantes com os ensinamentos do Evangelho, da Tradição viva e do perene Magistério da Igreja - estamos convencidos, nós e os senhores, de que a Teologia da Libertação é não só oportuna, mas útil e necessária”. El cardenal Müller recuerda que "a teologia da libertação é totalmente rejeitada somente por poucos teólogos, à parte aqueles que na sociedade, no Estado e, em parte também na Igreja, temem por seus privilégios. Do lado magisterial e doutrinal, apenas alguns elementos teóricos isolados encontram uma avaliação crítica, ou seja, exigem-se, em alguns pontos, ulteriores diferenciações" (L. G. Müller, "A controvérsia em torno da teologia da libertação", en G. L. Müller y G. Gutiérrez, Ao lado dos pobres, o. c., p. 104). 
hay que olvidar que la Iglesia no se reduce al magisterio", el cual "no está por encima de la palabra de Dios, sino a su servicio" ( $D V 10)$; que este tampoco está exento de equívocos y desvíos, y, por tanto, también está llamado a la conversión; y que la teología tiene una función crítica en relación con el magisterio ${ }^{20}$.

\section{El tema}

La discusión sobre el tema de la teología de la liberación es fundamental y necesaria. Fundamental, porque explicita lo que es propio de dicha teología y porque determina, en buena medida, el método o el camino que debe recorrer, al desarrollar y elaborar una teoría teológica. Necesaria por esa razón y por la divergencia y confusión, en torno a su argumentación.

Desde el comienzo, el contenido de la teología de la liberación ha suscitado diferencias y tensiones, tanto en la Iglesia, en general, como también entre los mismos teólogos de la liberación. Básicamente, existen dos enfoques. Uno de ellos aparece en la obra clásica de Gustavo Gutiérrez y es defendido por la mayoría de los teólogos de la liberación. Este enfoque plantea "no tanto un tema nuevo para la reflexión cuanto una nueva manera de hacer teología" ${ }^{21}$. Más que un tema específico, la liberación es tomada como un horizonte para desarrollar la teología en su totalidad ${ }^{22}$. La otra perspectiva, predominante en el imaginario eclesial y social, fue formulada y defendida de manera muy particular

19. En su obra clásica $O$ novo povo de Deus, Ratzinger critica lo que llama la "teología de encíclica", es decir, "um tipo de teologia que se restringia cada vez mais a escutar e a analisar as declarações e os documentos papais" (J. Ratzinger, O novo povo de Deus, p. 267, São Paulo: Paulinas, 1974). Frente a esa teología, según él, el concilio vuelve a considerar "todas as fontes" de la teología y "mostrou também que a teologia não deve considerar todas as fontes apenas através do filtro da interpretação do magistério dos últimos cem anos, mas que as deve ler e procurar compreendêlas como são em si mesmas. O Concílio expressou, inclusive, o desejo de não dar atenção apenas à tradição católica, como de estudar também seriamente o desenvolvimento da teologia de outras Igrejas e de outras denominações cristãs" (ibidem).

20. La problemática de las relaciones entre la teología y el magisterio fue abordada por la Comisión Teológica Internacional, en la sesión plenaria de 1975 ( $c$ fr. "As relações entre Magistério Eclesiástico e Teologia”, $R E B$ 144 [1976], 947-959). El tema reaparece en un contexto más amplio, la discusión del estatuto de la teología católica, en la sesión plenaria de 2011. Cfr. Teologia hoje: perspectivas, princípios e critérios (São Paulo: Paulinas, 2013).

21. G. Gutiérrez, Teologia da libertação, o. c., p. 73.

22. Cfr. J. C. Scannone, Teología de la liberación y praxis popular, p. 18 (Salamanca: Sígueme, 1976); J. L. Segundo, Libertação da teologia, o. c., p. 5, n. 1; I. Ellacuría, "Teología de la liberación frente al cambio socio-histórico en América Latina", en Escritos teológicos I, p. 315 (San Salvador: UCA Editores, 2000); L. Boff, Teologia do cativeiro e da libertação, pp. 27, 50, 54 (Petrópolis: Vozes, 1983). 
por Clodovis Boff. Este teólogo entiende la teología de la liberación como una "teología de lo político" o de las cuestiones sociales. En este sentido, es una teología parcial, o sea, un momento o una parte de la teología ${ }^{23}$.

Evidentemente, si la teología de la liberación fuera una teología de lo político o de las cuestiones sociales, solo trataría un aspecto de la revelación y de la fe, por más fundamental y determinante que este sea, y presupondría, de alguna forma, elaboraciones teológicas desarrolladas no necesariamente a partir de los pobres y oprimidos y con vistas a su liberación. No debemos olvidar que buena parte de la teología fue hecha o acabó sirviendo para justificar las más diversas formas de opresión y dominación. La posición de Clodovis Boff, aunque no sea consecuente con la totalidad de la teología efectivamente desarrollada -las cuestiones y temas tratados - y no responda satisfactoriamente a la problemática de la teología presupuesta -dominación versus liberación-, es coherente con su concepción de teología de la liberación - teología de lo político- y con su método -mediaciones socio-analíticas, hermenéuticas y prácticas.

Ahora bien, por más relevancia y centralidad que las cuestiones sociales y políticas tengan en las diversas teologías de la liberación, estas nunca tratarán solo de esas cuestiones. Al contrario, trataron y tratan de las más diversas cuestiones y temas, como la cristología, trinidad, pneumatología, espiritualidad, eclesiología, pastoral, liturgia, sacramentos, etc., y de modo especial, cuestiones sociales, políticas, culturales, de género, sexuales, étnico-raciales, ecológicas, religiosas e interreligiosas, etc. $Y$ lo hacen a partir de los pobres y oprimidos, en sus luchas por la liberación.

En este sentido, se debe afirmar que la teología de la liberación no es meramente una "teología de lo político" o de las cuestiones sociales, tal como pretende y propone Clodovis Boff. Por más relevancia y prioridad que dé a estas cuestiones, la teología de la liberación es inteligencia de la fe en su totalidad, a partir de los pobres y oprimidos, con vistas a su liberación. Este enfoque está en perfecta sintonía con la revelación y la fe bíblicas, las cuales operan en la comunidad eclesial como canon y regla de la fe vivida y pensada.

El tema de la teología de la liberación es, por tanto, la fe en su totalidad, esto es, la comunión con Dios, o la vida en su totalidad, vivida en y según Dios, tal como se reveló en la historia de Israel y, definitivamente, en la praxis de Jesús de Nazaret. Así, trata de todos los temas o cuestiones (totalidad), desde la tradición

23. Cfr. C. Boff, Teologia e prática, o. c.; Teoria do método teológico, o. c., pp. 17s, 637s; "Como vejo a teologia latino-americana trinta anos depois", en L. C. Susin (coord.), O mar se abriu, o. c., pp. 89-92; "Retorno à arché da teologia", en L. C. Susin (coord.), Sarça ardente. Teologia na América Latina: prospectivas, pp. 180ss (São Paulo: Paulinas, 2000); y "Teología", en J. J. Tamayo, Nuevo diccionario de teología, pp. 867s (Madrid: Trotta, 2005). 
de Jesús de Nazaret, que tiene en los pobres y los oprimidos su medida y sus criterios históricos (especificidad).

Si buscamos un concepto que pueda dar cuenta tanto de su carácter englobante o totalizante como de su especificidad práctico-teórica, tendríamos que hablar de una teología de la "historia de la salvación" o del "reinado de Dios"24. Ambos refieren a la vida humana en su totalidad y vivida en comunión con Dios y de acuerdo con sus designios (Dios y el pueblo); ambos tienen una dimensión histórica constitutiva, que se materializa y se mide en la justicia a los pobres y oprimidos, como práctica liberadora (liberación); ambos poseen una dimensión escatológica fundamental, que mantiene la vida y la historia humanas siempre abiertas, incluso más allá de sí mismas (trascendencia).

Las teologías de la liberación no se diferencian de las otras teologías por un tema específico - pobre, mujer, negro, indígena, ecología, liberación, etc.-, sino por el modo de tratar cualquier tema, a saber, la aproximación histórico-liberadora. Todo lo piensa a partir de y con la finalidad de la salvación o del reinado de Dios, cuya medida y criterio histórico-escatológico se encuentra en los pobres y oprimidos. Esto tiene enormes implicaciones y consecuencias epistemológicas, como veremos enseguida. Curiosamente, esa es la perspectiva bíblica. Pero perdió relevancia y densidad teórico-teológicas en el contexto del proceso de constantinización de la Iglesia - la alianza con los imperios y los poderes- y en el de la tradición del pensamiento idealista y universalista, que idealiza y universaliza la historicidad de la salvación y la parcialidad del Dios - el pensamiento greco-occidental.

\section{Interés y orientación práctica}

No obstante las distintas concepciones de la práctica y de su relación con la teoría, los teólogos de la liberación siempre han entendido la teología de la liberación como una teología de la práctica: "un momento del proceso por medio del cual el mundo es transformado" (Gustavo Gutiérrez) ${ }^{25}$; una especie de praxeología de la liberación (Hugo Assmann)26; un "momento consciente y reflexivo de la praxis eclesial" (Ignacio Ellacuría)27; una "teología de lo político y sus

24. Cfr. F. Aquino Júnior, "O reinado de Deus como assunto da teologia cristã”, $R E B 281$ (2011), 47-68.

25. G. Gutiérrez, Teologia da libertação, o. c., p. 74.

26. Cfr. H. Assmann, Teología desde la praxis de la liberación. Ensayo teológico desde la América dependiente, pp. 62-65 (Salamanca: Sígueme, 1973).

27. Cfr. I. Ellacuría, "La teología como momento ideológico de la praxis eclesial", en Escritos teológicos I, o. c., pp. 163-185. 
mediaciones" (Clodovis Boff) ${ }^{28}$; una "intellectus amoris" (Jon Sobrino) ${ }^{29}$, entre otros. Todas las teologías de la liberación -feminista, negra, indígena, ecológica, religiosa e interreligiosa, gay, etc.- están vinculadas a procesos históricos de liberación.

La referencia fundamental a la praxis está relacionada, ante todo, con la acción pastoral-evangelizadora de la Iglesia, en particular, con su dimensión socio-liberadora, vinculada a las luchas y a los movimientos populares ${ }^{30}$. Asimismo, tiene muchas implicaciones y consecuencias epistemológicas, que no son fáciles de captar y que entran en conflicto con la concepción hegemónica del saber, desarrollada a lo largo de la tradición occidental. Esta tradición está marcada por el dualismo, más o menos radical, por el maniqueísmo, entre sentido e inteligencia, y por una concepción idealista del saber.

Gustavo Gutiérrez intuyó, incluso esbozó, esa problemática epistemológica de la teología, en su respectividad con la praxis ${ }^{31}$. Sin embargo, Ignacio Ellacuría parece ser el teólogo de la liberación que desarrolló y formuló esa problemática más amplia y consecuentemente ${ }^{32}$. Y lo hizo desde la teoría de la inteligencia de Xavier Zubiri (Inteligencia sentiente ${ }^{33}$ ).

A diferencia de otros modos de hacer teología, cuya preocupación y orientación fundamentales consisten en la búsqueda y la "comprensión del sentido" de las afirmaciones dogmáticas o de la positividad de la fe (interpretación), la preocupación y la orientación fundamentales de la teología de la liberación, según Ellacuría, residen en la realización histórica de la salvación, esto es, en la "transformación de la realidad y, en ella, la transformación de la persona" (praxis). Frente a teologías predominantemente "intelectualistas", centradas en las ideas, en el diálogo cultural, en la lógica discursiva, etc., la teología de la

28. Cfr. C. Boff, Teologia e prática, o. c.

29. Cfr. J. Sobrino, El principio-misericordia: bajar de la cruz a los pueblos crucificados, pp. 47-80 (Santander: Sal Terrae, 1992).

30. Cfr. G. Gutiérrez, $A$ verdade vos libertará, o. c., pp. 27-32; y "A teologia, um função eclesial", en $A$ densidade do presente, pp. 29-40 (São Paulo: Loyola, 2008).

31. Cfr. G. Gutiérrez, "Teologia: Reflexão crítica", en Teologia da libertação, o. c., pp. 57-74; y "Verdade e teologia", en A verdade vos libertará, o. c., pp. 107-128.

32. Cfr. I. Ellacuría, "La teología como momento ideológico de la praxis eclesial", o. c., pp. 163-185; "Hacia una fundamentación del método teológico latinoamericano", en Escritos teológicos I, o. c., pp. 187-218; "Relación teoría y praxis en la teología de la liberación", ibid., pp. 235-245; F. Aquino Júnior, A teologia como intelecção do reinado de Deus, o. c., pp. 213-264; y "O caráter práxico da teologia: abordagem epistemológica”, Perspectiva Teológica 119 (2011), 83-102.

33. Cfr. X. Zubiri, Inteligência e realidade (São Paulo: É Realizações, 2011); Inteligência e logos (São Paulo: É Realizações, 2011); e Inteligência e razão (São Paulo: É Realizaçōes, 2011). 
liberación es una teología predominantemente "realista" y práxica, centrada en la realidad - no en la idea o el concepto de esa realidad-, que procura inteligir en su realización histórica, esto es, en la búsqueda de mediaciones concretas $-\mathrm{y}$ no solo en la búsqueda de su sentido ${ }^{34}$ - que la efectivicen. Ciertamente, la teología de la liberación se interesa en el sentido de las afirmaciones teológicas, pero en función de su realización histórica, como un momento del proceso de realización de la salvación.

La afirmación del primado de la praxis sobre el sentido no es gratuita. No está hecha en función del activismo pastoral o político, y en perjuicio de la actividad estrictamente teórica. Sino que se fundamenta en el análisis de la intelección humana. En contra de lo que se acostumbra pensar, la intelección no es primariamente una especulación (teórica), sino un modo de enfrentamiento (praxis), y no consiste formalmente en una "comprensión de sentido", sino en una "aprehensión de realidad" 35 . Es claro que todas las cosas, en tanto que aprehendidas intelectivamente, adquieren algún sentido en la vida humana, el cual es necesario explicitar. Pero el sentido, en cuanto sentido de la cosa aprehendida, está fundado en la cosa misma y su interpretación presupone su aprehensión. De modo que, primaria y formalmente, la intelección consiste en "aprehender la realidad" y en "enfrentarse con ella" como "realidad" 36 .

La misma intuición fue formulada, con un lenguaje más teológico y coloquial, por Jon Sobrino. Este teólogo comprende la teología como una intellectus amoris, esto es, como una inteligencia de la realización del amor histórico por los pobres, que nos torna afines a la realidad de Dios ${ }^{37}$. Este concepto se encuentra

34. Cfr. I. Ellacuría, "Hacia una fundamentación del método teológico latinoamericano", o. c., p. 200.

35. Cfr. ibid., pp. 202-211.

36. Cfr. ibid., pp. $207 \mathrm{~s}$.

37. Cfr. J. Sobrino, "Teologia num mundo sofredor. A teologia da libertação como 'intellectus amoris", en O princípio misericórdia: descer da cruz os povos crucificados, pp. 71-76 (Petrópolis: Vozes, 1994). Si "como foi repetido à saciedade, a revelação de Deus não consiste formalmente na comunicação de verdades plurais acerca de si mesmo, mas na doação de sua própria realidade e, correlativamente, a resposta a essa revelação não consiste primariamente na aceitação de verdades -e sua ulterior compreensão e aprofundamento-, mas na acolhida real desse Deus, tornando historicamente real a realidade transcendente desse Deus" (p. 73); "não se vê porque a teologia tenha de ser compreendida só como intellectus fidei [explicação e aprofundamento dos conteúdos positivos da fé] nem, menos ainda, ser reduzida a isso. Nảo se vê porque a atividade teológica, mais uma entre as atividades cristãs, não deva dar prioridade ao que caracteriza a revelação e a fé cristã: o amor" (p. 74). "Por isso queremos propor que a teologia, enquanto intellectus, compreenda a si mesma a partir da totalidade da tríade fé-esperança-amor, e que, dentro dela, dê prioridade ao amor" (p. 74). 
esbozado en el último documento de la Comisión Teológica Internacional, sobre el estatuto de la teología católica, a partir de la tríada fe-esperanza-caridad ${ }^{38}$. Y aparece, de alguna forma, en perspectiva y lenguaje pastoral, en la exhortación apostólica del papa Francisco La alegría del evangelio, al afirmar que "la realidad es más importante que la idea" ( $E G$ 231ss) $)^{39}$. Sin hablar de su profunda sintonía con la epistemología bíblica ${ }^{40}$, según la cual conocer a Dios, por ejemplo, es vivir en comunión con él y realizar su voluntad (Jr 22,16; 1 Jn 2,4ss; 4,8).

Asumir con seriedad el carácter fundamentalmente práxico de la teología conlleva enormes consecuencias para el quehacer teológico, para el producto teológico y para la fecundidad y la eficacia pastoral de la teología. El interés y la orientación fundamentales de una teología cualquiera determinan decisivamente su proceso, su resultado y su utilidad.

Si la teología partiera, por ejemplo, de la pregunta por el sentido de la vida, el diálogo cultural entre las distintas cosmovisiones se situaría en el primer plano de interés, mientras que otros problemas humanos se relegarían a un segundo plano o se excluirían del plano de la teología.

$\mathrm{Si}$, por el contrario, parte de un interés y de una orientación práxicas, el acento cae en las posibilidades y las mediaciones para su realización histórica.

38. "Em razão da estreita relação entre fé, esperança e amor, pode-se afirmar que a teologia é também [além de fides quaerens intellectum] spes quaerens intellectum (cfr. $1 \mathrm{Pd} 3,15)$ e caritas quarens intellectum. Este último aspecto recebe relevo particular no cristianismo do Oriente: como a teologia explica o mistério de Cristo, que é a revelação do amor de Deus (cfr. Jo 3,16), ela é o amor de Deus escrito em palavras" (Comisión Teológica Internacional, Teologia hoje: perspectivas, princípios e critérios, o. c., núm. 19, nota 27).

39. Entre la idea y la realidad, "deve estabelecer-se um diálogo constante, evitando que a ideia acabe por separar-se da realidade. É perigoso viver no reino só da palavra, da imagem, do sofisma [...] a realidade é superior à ideia. Isto supõe evitar várias forma de ocultar a realidade" ( $E G$ 231). "A ideia - as elaborações conceituais- está ao serviço da captação, compreensão e condução da realidade. A idéia desligada da realidade dá origem a idealismos e nominalismos ineficazes que, no máximo, classificam ou definem, mas não empenham. O que empenha é a realidade iluminada pelo raciocínio. É preciso passar do nominalismo formal à objetividade harmoniosa" ( $E G$ 232). "A realidade é superior à ideia. Este critério está ligado à encarnação da palavra e ao seu cumprimento" ( $E G$ 233).

40. Cfr. H. Zimmermann, "Conhecimento", en J. Bauer, Dicionário de teologia bíblica VI, pp. 204-210 (São Paulo: Loyola, 1988); G. Ziener, "Palavra", ibid., pp. 794-798; J. Corban y A. Vanhoye, "Conhecer", en X. León-Dufour, Vocabulário de teologia bíblica, pp. 165-169 (Petrópolis: Vozes, 1972); y C. Boff, Teoria do método teológico, o. c., pp. 188-192.

Digitalizado por Biblioteca "P. Florentino Idoate, S.J."

Universidad Centroamericana "José Simeón Cañas" 
La elección adecuada del punto de partida [entendido como interés u orientación fundamental] de la teología puede determinar decisivamente la formulación del mensaje que el cristianismo quiere transmitir a una humanidad atravesada por enormes conflictos ${ }^{41}$.

\section{El lugar social}

La discusión sobre la problemática y la determinación del lugar social de la teología es relativamente reciente. En realidad, surge en el seno de la teología de la liberación, en sus enfoques más variados y en sus formulaciones más diversas ${ }^{42}$. Desde el principio, los teólogos de la liberación se dieron cuenta de la importancia del lugar social del quehacer teológico y de que el mundo de los pobres y oprimidos constituye el lugar social fundamental de la revelación, de la fe y de la teología cristianas. El contacto con las luchas populares y las ciencias sociales, históricas, antropológicas, hermenéuticas, etc., fue determinante para descubrir la importancia del lugar social en el quehacer teológico. El descubrimiento del mundo de los pobres y los oprimidos como lugar social de la teología ocurre a través de la teología bíblica y de su función canónica, en el conjunto de la teología. Los teólogos se confrontan con la problemática del lugar social de la teología, de manera progresiva. A veces, explicitando el lugar, o los lugares, que viene ocupando a lo largo de la historia, con la ayuda de las ciencias sociohistóricas; a veces, determinando teológicamente el lugar que debe ocupar. Las dos tareas son distintas, pero están relacionadas, pues una remite a la otra.

41. A. González, "La vigencia del 'método teológico' en la teología de la liberación”, Sal Terrae 983 (1995), 667-675, aquí 669.

42. Cfr. L. Boff, Jesus Cristo libertador: ensaio de cristologia crítica para o nosso tempo, pp. 15-37 (Petrópolis: Vozes, 1991); A fé na periferia do mundo (Petrópolis: Vozes, 1991); y Do lugar do pobre (Petrópolis: Vozes, 1997); C. Boff, Teoria e prática, o. c., pp. 281-303; I. Ellacuría, "Los pobres, 'lugar teológico' en América Latina", en Escritos teológicos I, o. c., pp. 139-161; "La Iglesia que nace del pueblo por el Espíritu”, en Escritos teológicos II, pp. 343-355 (San Salvador: UCA Editores, 2000); "El auténtico lugar social de la Iglesia", en Escritos teológicos II, o. c., pp. 439-451; J. Sobrino, Jesus, O Libertador: a história de Jesus de Nazaré, pp. 42-61 (Petrópolis: Vozes, 1996); L. C. Susin, “O privilégio e o perigo do 'lugar teológico' dos pobres na Igreja", en J. M. Vigil (coord.), Descer da cruz os pobres: cristologia da libertação, pp. 322-329 (São Paulo: Paulinas, 2007); "Os pobres como 'lugar teológico': uma questão hermenêutica crucial de nosso tempo", en Soter (coord.), Deus e vida: desafios, alternativas e o futuro da América Latina e do Caribe, pp. 151-180 (São Paulo: Paulinas, 2007); F. Aquino Júnior, A teologia como inteleç̧ão do reinado de Deus, o. c., pp. 265-318; "Sobre o conceito "lugar teológico", $R E B$ 278 (2010), 451-453; y "Lugar social da teologia", Perspectiva Teológica 125 (2013), 127-145. 
Así, pues, es necesario confrontarse críticamente con la historia de la teología, para explicitar el lugar social que viene ocupando. Aquí es fundamental preguntarse por el "para qué y para quién" de la teología, esto es, "a quién sirve" y "para qué, de hecho, sirve" una determinada teología ${ }^{43}$. No se trata de juzgar el pasado con criterios actuales, puesto que esa tarea comprende también las más diversas teologías producidas en el presente. Se trata, simplemente, de identificar el lugar social de las diversas teologías, pasadas y presentes, con las cuales nos confrontamos. Esto es necesario por dos razones. La primera razón es una cuestión de criticidad y lucidez teóricas. Si toda teología se produce siempre a partir de y en referencia a un determinado lugar social, es importante y necesario identificar ese lugar social, para comprender mejor sus afirmaciones, sus objetivos y sus mediaciones práctico-teóricas. La segunda razón es estrictamente teológica, ya que se trata de analizar su legitimidad y su fundamento teológico. La historia de la Iglesia y, concretamente, la historia de la teología, no pueden ser reducidas a un elenco de acontecimientos, autores y teorías. Lo teológico de la aproximación a la historia de la Iglesia y, en ella, a la historia de la teología, consiste en analizar e interpretar los acontecimientos, los autores y las teorías desde, y en relación con, la salvación o la realización del reinado de Dios $^{44}$. Por eso, no es suficiente identificar el lugar social de una teología cualquiera, sino que, además, es necesario confrontarlo con el lugar social de la historia de la salvación, tal como ocurrió en Israel y, en particular, en la praxis de Jesús.

También es necesario determinar el lugar social que la teología debe ocupar. Esa tarea es obligatoria, tanto para la aproximación teológica a la historia de la Iglesia, y, en ella, a la historia de la teología, como para desarrollar una teología auténticamente cristiana. Si la identificación del lugar social de cualquier teología se hace, en particular, con la ayuda de las ciencias socio-históricas y su "sospecha teológica" - a quién o qué intereses sociales sirve, de hecho-, determinar su lugar social es una tarea estrictamente teológica -a quién o qué intereses debe servir. Esa tarea teológica se hace a partir de y en referencia al acontecimiento histórico que funciona como fundamento, "canon" y criterio de la praxis eclesial y de su momento más propiamente intelectivo, esto es, la teología: la historia de Israel y, en ella, la praxis de Jesús. A partir de aquí se puede y se debe justificar o criticar teológicamente el lugar social de toda teología, pasada o presente, del teólogo o del magisterio episcopal. A partir de aquí se evita el relativismo teológico, en la medida en que la discusión del lugar social de la teología ocurre con un criterio objetivo e históricamente verificable, más allá de todo subjetivismo e idealismo. Y es a partir de aquí que la teología deja de ser un instrumento

43. I. Ellacuría, "Hacia una fundamentación del método teológico latinoamericano", o. c., p. 214.

44. Cfr. I. Ellacuría, "Iglesia y realidad histórica", en Escritos teológicos II, o. c., pp. 501-515. 
ideológico de las formas de opresión y dominación más diversas, y ejerce, de manera consecuente, la función profética que le compete en la sociedad, en cuanto momento consciente y reflexivo de la salvación o del reinado de Dios en este mundo.

La problemática del lugar social de la teología es, ciertamente, el aspecto más complejo y más conflictivo, pero también el más bíblico, el más profético y el más eficaz de la teología de la liberación. Es el más complejo y el más conflictivo, porque toca intereses concretos y desenmascara la instrumentalización ideológica de la teología - no se debe olvidar que la teología fue y continúa siendo usada para legitimar diferentes formas de injusticia (económica, social, política, cultural, étnico-racial, religiosa, de género, sexual, ecológica, etc.). Es el más bíblico, porque recupera lo más característico de la acción de Dios y de la relación con él, en la historia de Israel y en la práctica de Jesús de Nazaret: el derecho y la justicia de los pobres y oprimidos. Es el más profético y la más eficaz, porque se confronta con situaciones históricas actuales de injusticia y opresión, y porque favorece, teórica y prácticamente, procesos históricos concretos y actuales de liberación.

La objeción más común que esta discusión plantea a la teología de la liberación es que compromete la universalidad de la salvación. Curiosamente, esta objeción es, por lo general, planteada, explícita o implícitamente, desde y en función de las clases o los sectores dominantes de la sociedad. Esto demuestra, una vez más, cómo una teología, consciente o incónscientemente, siempre es hecha desde algún lugar social. No existe una teología socialmente neutra. De una $\mathbf{u}$ otra forma, termina favoreciendo a determinados intereses sociales $y$ desfavoreciendo a otros. En todo caso, conviene recordar que el lugar social de la teología está determinado por el lugar social de la revelación y de la fe, que, de acuerdo con la Escritura, no es otro que el de los pobres y oprimidos, y sus procesos de liberación. Este lugar social no compromete la universalidad de la salvación, sino que apenas determina el "desde dónde" - los pobres y los oprimidos- y el "cómo" - los procesos de liberación- de su realización histórica. Esto es válido para todos (universalidad), pero se realiza desde los pobres y los oprimidos, y sus procesos de liberación (parcialidad).

\section{Algunos retos actuales}

A modo de conclusión, señalo algunos retos actuales de la teología de la liberación, relacionados con su estatuto teórico-teológico. Aunque este no es el lugar apropiado para desarrollarlos, considero importante señalarlos. Así, pues, dejo para otra ocasión su tratamiento, en el contexto de la profundización y reformulación de la teología de la liberación y sus presupuestos epistemológicos. 


\subsection{La tradición de Jesús de Nazaret}

Toda teología está constitutivamente vinculada a una determinada experiencia de Dios en la historia y se desarrolla como inteligencia de esa experiencia concreta de Dios, fuente de la que deriva su fuerza y su vigor. La teología de la liberación nació y se desarrolló en el seno de comunidades cristianas de tradición occidental. Más tarde, extrapoló esa frontera cultural y religiosa y se ha desarrollado también en el seno de comunidades indígenas, afro-americanas, musulmanas, judías, budistas, etc. Más allá de la comunión que pueda haber entre las diversas teologías de la liberación, cada una de ellas está marcada — posibilitada, condicionada, determinada - por la tradición en la que se inserta. Desentenderse de esa tradición, es desentenderse de su fuente y renunciar a su vocación de inteligencia de la fe.

Ciertamente, la tradición es un proceso histórico, dinámico, creativo e interactivo. Por eso, las diversas tradiciones religiosas pueden interactuar entre ellas y crecer. Pero eso, no puede implicar la negación o la ruptura con la propia tradición, ni mucho menos caer en la tentación idealista de crear artificialmente una súper-tradición, una especie de "esperanto" religioso o teológico, que sobrevuele por encima de las tradiciones concretas - las únicas que existen, de hecho. La ampliación de las tradiciones, la adquisición de configuraciones históricas nuevas y el crecimiento y enriquecimiento en la interacción con las otras tradiciones no puede suponer su negación y su destrucción.

Nosotros nos situamos en la tradición de Jesús de Nazaret y, desde ella y en ella, nos encontramos con personas y comunidades vinculadas a otras tradiciones e interactuamos con ellas. Lo que nos caracteriza es el seguimiento de Jesús, dinamizado por el amor fraterno y la justicia a los pobres y oprimidos de este mundo. Este estilo de vida, que puede llevar al martirio, es el gran don que recibimos de Jesús y es lo que tenemos para ofrecer al mundo. Es un estilo de vida que, aunque propio, no es exclusivo del cristianismo. La teología cristiana no es más que la inteligencia de ese estilo de vida, que nos hace cercanos a Dios.

El reto fundamental de la teología de la liberación consiste en mantener la fidelidad a la tradición de Jesús, en interacción con otras tradiciones religiosas y con la sociedad en general, siempre desde y en la perspectiva del amor fraterno y de la justicia a los pobres y oprimidos, la señal del reinado de Dios en este mundo.

\subsection{Complejidad del horizonte y de los procesos de liberación}

Indudablemente, la liberación es la característica más peculiar del movimiento teológico-pastoral conocido como teología de la liberación. El nombre no es casual, porque dice tanto respecto a la praxis socio-eclesial como a la teoría teológica. Por eso, fue comprendida y desarrollada simultáneamente como "teología de la liberación" (Gutiérrez) y como "liberación de la teología" 
(Segundo). El nivel de complejidad dice tanto respecto a la praxis y la teoría como a la relación teoría-praxis.

Más allá de la problemática teoría-praxis, la complejidad de la liberación dice respecto a las diversas formas de opresión y, en consecuencia, a los diversos procesos de liberación, en su especificidad y unidad radical. En las décadas de 1970 y 1980, la discusión se centró en las cuestiones sociales, políticas y económicas. A tal punto, que la teología de la liberación fue acusada de reducir todo a política o economía. A partir de la década de 1980 y, sobre todo, de la de 1990, emergieron y se impusieron las cuestiones de género, las étnico-raciales, las ecológicas, las interreligiosas y, más recientemente, las relacionadas con la diversidad sexual. En este contexto, más que de teología de la liberación sin más, se ha hablado de diversas teologías de la liberación - teología feminista, negra, indígena, ecológica, interreligiosa o gay. La complejidad remite a la diversidad de aspectos o dimensiones de la vida humana, en lo que tiene de irreductible - aspectos y dimensiones - y de unidad radical - vida humana. También remite a la diversidad de mediaciones teóricas y prácticas de cada una de esas teologías.

Al llegar a este punto, surgen algunas cuestiones ineludibles. Cómo no perder de vista la complejidad de la vida humana, al priorizar uno de sus aspectos o una de sus dimensiones. Aun cuando la vida humana es irreductible a una de sus dimensiones, cómo hablar de una base material como condición para el desarrollo de las otras dimensiones, sin otorgar cierta primacía a lo económico. Cuáles son las mediaciones teóricas y prácticas más adecuadas para desarrollar las diversas teologías de la liberación, y cómo se complementan y condicionan entre ellas.

\subsection{El carácter teologal de los procesos de liberación}

Un presupuesto fundamental de la teología de la liberación es que los procesos de liberación, además de procesos sociales, políticos, económicos, culturales, de género, etc., son procesos estrictamente teologales. Procesos que remiten, positiva o negativamente, a Dios y a su acción salvífica o a su reinado en la historia. Pero este presupuesto no es obvio e intranquiliza a la Iglesia.

No se debe olvidar que la tradición teológica occidental está marcada por un dualismo más o menos radical, incluso por un maniqueísmo, manifiesto de modo particular en la oposición materia y espíritu. A lo largo de la historia, se encuentran varias versiones de ese maniqueísmo: humano y divino, gracia y libertad, natural y sobrenatural, inmanencia y trascendencia, liberación y salvación.

Tanto el concilio como la teología postconciliar dieron pasos significativos para superar ese dualismo. Pero aun así, se siguió hablando de historia profana e historia sagrada - ¡incluso K. Rahner!-, de realidades terrestres y misión espiritual, de humano y divino, etc. Indudablemente, la cuestión no está resuelta, 
ni es una cuestión fácil de superar, sobre todo, en una cultura dualista como la nuestra, marcada por una manera disyuntiva de pensar $(0,0)$ y de decir (A es B), la cual tiende siempre a reducir la complejidad a uno de sus aspectos o dimensiones.

La teología de la liberación se inserta en este movimiento teológico postconciliar y, tal como lo reconoce el cardenal Müller, ha contribuido enormemente a la superación "del dilema dualista entre lo terreno y el más-allá, entre el bienestar terreno y la salvación eterna"45. Dentro de esa tradición conciliar, afirma insistentemente que "la lucha por la justicia y por la libertad humana [...] forma parte [...] de la esencia de la salvación". Pero, como lo reconoce Juan Luis Segundo,

no insistió lo bastante en el fundamento teológico de esa vuelta [a lo humano] exigida por el concilio. La teología de la liberación siguió como si aquella vuelta [a lo humano] hubiera acontecido y hubiera sido aceptada por la Iglesia entera y, de modo especial, por la jerarquía, cuya gran mayoría había firmado el texto ${ }^{46}$.

Tal vez la crítica teológica más fuerte contra la teología de la liberación se sitúe, precisamente, en este contexto de la superación del dualismo. En efecto, se reduciría a un inmanentismo historicista o, peor aún, reduciría todo a lo político. En el fondo, es la misma crítica hecha al concilio, contra la cual reacciona Pablo VI, en su discurso en la última sesión, y es la misma crítica hecha a Rahner: una especie de antropocentrismo teológico-pastoral, que comprometería la trascendencia de Dios. Y, aquí, nos parece, está una de las tareas y uno de los desafíos teológicos más importantes para la teología de la liberación: explicitar y formular, del modo más amplio y riguroso posible, el carácter teologal de los procesos históricos, particularmente, de los procesos históricos de liberación.

\subsection{La complejidad del proceso de intelección}

La teología es inteligencia de la fe o de la salvación, o del reinado de Dios. En este sentido, es un ejercicio intelectual, una actividad intelectiva. Pero lo que sea y cómo se desenvuelva ese ejercicio intelectual, o esa actividad intelectiva, es algo extremamente complejo, tal como lo muestran los debates y las teorías sobre la teología, sobre el quehacer teológico y sobre el método teológico.

El primer aspecto de esa complejidad es la respectividad del quehacer teológico (actividad intelectiva) y la realidad teologal (realidad inteligida). La teología

45. G. L. Müller, “A controvérsia em torno da Teologia da Libertação”, o. c., p. 109.

46. J. L. Segundo, "Críticas y autocríticas de la teología de la liberación”, en J. Comblin, J. I. González Faus y J. Sobrino, Cambio social y pensamiento cristiano en América Latina, pp. 218, 219 (Madrid: Trotta, 1993). 
no nace de sí misma, ni sobrevuela sobre sí misma; no es teoría de la teoría. Es inteligencia de la fe o de la salvación, o del reinado de Dios, y como tal, es un momento de la vida y la praxis del creyente y de la comunidad de fe (momento inteligente), y está constitutivamente referida a la realidad teologal (inteligencia de). Por más irreductible que sea la actividad intelectiva, esta es inseparable de los demás aspectos o momentos de la vida y la praxis humana, como, por ejemplo, los sentidos y la voluntad. Pero esto inquieta a la tradición occidental, marcada por un dualismo, más o menos radical, entre inteligencia y sensibilidad. Basta ver las tensiones y oposiciones surgidas a lo largo de la tradición (fe y razón, intellectus y ratio, amor y saber, voluntad y entendimiento) y las sospechas actuales, en torno al aspecto cordial, emocional y sentiente del proceso de intelección, en general, y teológico, en particular.

El segundo aspecto de esa complejidad está relacionado con los modos de inteligencia de la fe y con el lenguaje teológico. Antes de todo, es necesario reconocer que la inteligencia de la fe no se restringe a lo que clásicamente se llama teología. También se da a través o en forma de mitos, historias, arte, liturgia, ejercicios de piedad, etc. Más allá de eso, su lenguaje no se limita al lenguaje teórico-conceptual, propio de la filosofía occidental, sino que también se despliega, y de modo especial, en lenguaje narrativo, sapiencial, simbólico, etc. Las teologías feminista, negra, indígena, gay, son particularmente sensibles a esos modos de inteligir y a esas formas de lenguaje, lo cual no se opone necesariamente al modo teórico-conceptual de inteligencia de la fe, propio de la tradición filosófica occidental.

Más allá del vínculo esencial y constitutivo del quehacer teológico y la praxis teologal (inteligencia-sentidos), debemos distinguir y considerar el doble sentido de la palabra teología (diversos modos de inteligencia). En sentido amplio, la teología refiere a la inteligencia de la fe, que se realiza de muchos modos -mitos, historias, arte, liturgia, y también logos - y en diversos lenguajes - narrativos, simbólicos, y también conceptos. En sentido estricto o clásico, teología es un modo de inteligencia de la fe (logos griego), con determinado lenguaje teóricoconceptual. Estas modalidades de inteligencia y estas formas de expresión no necesariamente se contraponen. Más aún, pueden incluso complementarse mutuamente y ofrecer así accesos diferenciados a la realidad teologal.

\subsection{La tendencia al "docetismo"}

En 2000, la Sociedad de Teología y Ciencias de la Religión de Brasil (Soter) organizó un congreso continental para conmemorar los treinta años de la teología de la liberación en América Latina, y para confrontar los problemas y desafíos actuales y las perspectivas que se abrían al comienzo del nuevo milenio. Los organizadores solicitaron a varios teólogos hacer memoria de esos treinta años 
y de su trayectoria a lo largo de ese proceso, y señalar algunos desafíos actuales para la teología.

Jon Sobrino escribió un texto autobiográfico, titulado "Teología desde la realidad", que concluye con "algunas preocupaciones". La primera es lo que él llama la "tendencia al docetismo" de la teología actual.

Lo que más me preocupa en la teología es su tendencia al docetismo, esto es, a crear un ámbito propio de realidad que la distancie y la desentienda de la realidad real, allí donde pecado y gracia se hacen presentes. Ese docetismo, que normalmente es inconsciente, puede llevar al aburguesamiento, esto es, a prescindir de los pobres y las víctimas que son mayoría en la realidad y son la realidad más flagrante ${ }^{47}$.

En verdad, el ambiente social y eclesial poco favorable, incluso contrario, a los procesos de liberación, y la tentación constante de la erudición y del academicismo, propios del mundo universitario, hicieron que muchos teólogos se distanciasen de los procesos sociales y eclesiales y se concentrasen en el mundo de los libros y las teorías. De esa manera, elaboraron discursos y teorías, algunas de ellas bastante progresistas, como buena parte de la teología europea, pero desconectados de los procesos sociales y eclesiales, y, por esa razón, poco eficaces. Más que "un momento del proceso por medio del cual el mundo es transformado: abriéndose al don del reino de Dios", como proponía Gutiérrez ${ }^{48}$, la teología se va constituyendo como un mundo aparte, como escuela teológica, como movimiento de ideas, como sistema teórico, que vive de sí y por sí, "abandonando, así, lo que fue su intuición original: ser una reflexión vinculada a la vida de la comunidad eclesial. La vida [...] precediendo y provocando la reflexión teológica"49. Ya a comienzos de la década de 1980, el padre Arrupe, superior general de los jesuitas, muy ligado a la teología de la liberación, en una visita a Centroamérica, afirmaba tener la impresión de que la teología de la liberación "estaba perdiendo el push, que estaba tornándose demasiado académica"so.

Sin hablar de la tentación de la moda o de la novedad cultural, con sus plateas e índices altos de audiencia que, en la mejor de las hipótesis, relegan a los pobres y oprimidos, sus sufrimientos y sus procesos de liberación, a cuestiones secundarias, que ya no despiertan interés... Todos conocemos a teólogos progresistas, desvinculados de los procesos sociales y eclesiales, concentrados en termas que

47. J. Sobrino, "Teología desde la realidade", en L. C. Susin (coord.), O mar se abriu, o. c., p. 168.

48. G. Gutiérrez, Teologia da libertação, o. c., p. 74.

49. C. Palácio, "Trinta anos de teologia na América Latina: Um depoimento", en L. C. Susin (coord.), O mar se abriu, o. c., p. 60.

50. Cfr. I. Ellacuría, "Iglesia en Centroamérica", en Escritos teológicos II, o. c., p. 779. 
consideran más actuales y atractivos que la vida de los pobres y oprimidos, y sus procesos de liberación.

No se trata de ningún tipo de pragmatismo o activismo social y pastoral. Se trata apenas de tomar en serio algo que resulta determinante para el quehacer teológico: constituirse en el momento inteligente de la fe o de la salvación, o del reinado de Dios, cuya característica más determinante es la justicia a los pobres y oprimidos, $\mathrm{y}$, por tanto, ligarse constitutivamente a los procesos sociales y eclesiales de liberación. 